\title{
Effect of maternal low-protein diet and taurine on the vulnerability of adult Wistar rat islets to cytokines
}

\author{
S. Merezak ${ }^{1}$ B. Reusens ${ }^{1} \cdot$ A. $\operatorname{Renard}^{1} \cdot$ K. Goosse ${ }^{1}$ L. Kalbe ${ }^{1} \cdot$ M. T. Ahn ${ }^{1} \cdot$ J. Tamarit-Rodriguez $^{2}$. \\ C. Remacle Rem $^{1}$ \\ ${ }^{1}$ Laboratory of Cell Biology, World Health Organization Collaborating Centre for the Biology of Development of the Endocrine \\ Pancreas, Université Catholique de Louvain, Louvain-La-Neuve, Belgium \\ 2 Department of Biochemistry, Faculty of Medicine, Universidad Complutense, Madrid, Spain
}

\begin{abstract}
Aims/hypothesis. A maternal low-protein diet has been shown to induce an increased susceptibility of fetal islets to cytokines, but this effect can be avoided by maternal taurine supplementation. Here, we question whether these effects persist until adulthood in the offspring, despite the animal having a normal diet after weaning.

Methods. Pregnant Wistar rats received a diet of either $20 \%$ or $8 \%$ protein (control [C group] and recuperated [R group] respectively), which was or was not supplemented with taurine (control treated with taurine [CT group] and recuperated treated with taurine [RT group] respectively) during gestation and lactation. When the female offspring reached adulthood, an OGTT was performed. In a second stage, islets were isolated from these offspring, then pretreated or not with taurine, and subsequently treated with cytokines. Results. Fasting glycaemia was higher $(p<0.05)$ and insulinaemia was lower $(p<0.01)$ in the $\mathrm{R}$ group than in the $\mathrm{C}$ group. Taurine supplementation decreased insulinaemia in the CT group and tended to increase it in the RT group. After the OGTT, glycaemia in R ani-
\end{abstract}

mals was not different from that in the $\mathrm{C}$ group, despite a blunted insulin response $(p<0.05)$ which was restored by taurine. Supplementation in C-group mothers led to a weak glucose intolerance. In vitro, more apoptotic cells were observed in $\mathrm{R}$ islets after cytokines treatment $(p<0.01)$. The addition of taurine to the culture medium in the $\mathrm{R}$ and $\mathrm{C}$ groups protected the islets from the cytokines $(p<0.01)$. Maternal taurine supplementation decreased the sensitivity of islets in the RT group $(p<0.01)$, but increased sensitivity in the CT group $(p<0.01)$.

Conclusions/interpretation. The increased vulnerability of islets to cytokines due to a restriction of protein during fetal development was still evident when the offspring reached adulthood. The low-protein diet also induced hyperglycaemia in the presence of lower insulinaemia. Taurine supplementation protected adult islets of the $\mathrm{R}$ group from cytokine toxicity and restored the insulinaemia. However, unnecessary supplementation of taurine could have detrimental effects.

Keywords Adult islets - Cytokines .

Maternal low-protein diet - Taurine
Received: 19 November 2003 / Accepted: 9 January 2004 Published online: 10 March 2004

C) Springer-Verlag 2004

C. Remacle ( $)$

Laboratory of Cell Biology,

World Health Organization Collaborating Centre

for the Biology of Development of the Endocrine Pancreas,

Université Catholique de Louvain, Place croix du sud 5,

1348 Louvain-La-Neuve, Belgium

E-mail: remacle@bani.ucl.ac.be

Tel.: +32-10473522

Abbreviations: C, control - CT, control treated with taurine IL-1 $\beta$, interleukin- $1 \beta \cdot$ iNOS, inducible nitric oxide synthase $\mathrm{LP}$, low protein $\cdot \mathrm{NO}$, nitric oxide $\cdot \mathrm{R}$, recuperated .

$\mathrm{RT}$, recuperated treated with taurine

\section{Introduction}

Epidemiological data suggest that fetal malnutrition induces growth retardation in the offspring and degenerative diseases in adult life, including hypertension, cardiovascular disease, obesity, glucose intolerance and Type 2 diabetes mellitus [1]. These studies have led to the hypothesis that some programming of these pathologies is established in early life, due to the lack of fetal nutrient availability as a consequence of poor placental function or maternal malnutrition. To reveal mechanisms involved in this programming, we developed an animal model of maternal malnutrition. In this model, a low-protein (LP) diet ( $8 \%$ vs $20 \%$ control) given during gestation leads to offspring having 
lower body weight. Pancreatic beta cell mass, insulin content and insulin secretion are reduced at birth [2, $3]$. In addition, in vivo and in vitro, the proliferation rate of fetal islet cells is lower $[2,4,5,6]$, while apoptosis is higher $[5,6,7]$. Fetal LP islets exposed to interleukin-1 $\beta$ (IL-1 $\beta$ ) or to nitric oxide (NO) donor, toxic molecules implicated in beta cell damage in Type 1 diabetes, are more sensitive than control islets, showing that an LP diet in fetal and early life increases the vulnerability of fetal islets. Resuming a normal diet after birth or after weaning does not restore a normal plasma insulin level in the offspring, which is reduced in fasting state and after an oral glucose challenge in adulthood $[8,9]$.

The early LP diet also specifically affects some amino acid concentrations in plasma. In particular, taurine is severely reduced in both maternal and fetal plasma [10], as well as in fetal islets. Taurine (2-aminoethanesulphonic acid) is not incorporated into proteins. Nevertheless, the substance is found at high intracellular concentrations in most animal tissues. It is an end product of the metabolism of sulphur amino acids, methionine and cysteine [11]. Taurine is important for normal fetal development $[12,13]$ and is dependent on placental transfer from the mother [14]. At the cell level, the physiological role of taurine is not fully understood, although it has been implicated in osmoregulation, inhibition of protein phosphorylation and calcium modulation $[14,15]$. It is also reported to have a hypoglycaemic activity and to modulate insulin secretion $[16,17,18,19,20]$. Taurine plays an important role in the prevention of cell death; it has been found to prevent death of endothelial cells induced by TNF $\alpha$ and/or arsenite [21]. Moreover, Fas (CD95/APO-1)-mediated neutrophil apoptosis is reported to be inhibited by taurine through calcium homeostasis [22]. Finally, the substance appears to be important for the normal development of the endocrine pancreas, since supplementing a maternal LP diet with taurine has been found to restore a normal taurine concentration in fetal plasma, a normal beta cell mass and a normal insulin secretion by fetal islets $[5,23,24]$. In vivo and in vitro, taurine prevents the damage to fetal beta cells induced by IL-1 $\beta$ and NO [7].

In the present study, we asked whether the higher sensitivity of fetal islets to cytokines as well as the lower insulin secretion, both due to an LP diet during fetal development, persist until adulthood, and whether the preventive effect of maternal taurine supplementation is still evident in adult offspring rats.

\section{Materials and methods}

Animals. Wistar (WI-HAN) rats were bred in our animal husbandry. Adult virgin female rats were caged overnight with males (four females to one male), and copulation was verified the next morning. The animals were maintained at $25^{\circ} \mathrm{C}$ with a 10 -h to 14-h dark-light cycle. One group of pregnant rats was fed with a control diet ( $20 \%$ protein, C group), and a second group with an isocaloric LP diet ( $8 \%$ protein, $\mathrm{R}$ group). These diets were maintained until lactation. To investigate the effect of taurine in vivo, the pregnant rats were fed a control or LP diet supplemented with $2.5 \%$ taurine $(\mathrm{w} / \mathrm{v}$; in the drinking water) until lactation (CT and RT groups).

In each of the 5 newborn litters per group, all but 8 offspring were culled (160 animals). After weaning, the offspring in each of the four groups received a normal diet until 12 weeks after birth. The diet did not contain taurine, and its composition has been described previously [5]. The control and LP diets were purchased from Hope Farms (Woerden, Holland). All animals had free access to water.

All procedures were carried out in accordance with the 'Principles of laboratory animal care' (NIH publication no. 8523 , revised 1985) and with the approval of the animal ethics committee of the University of Louvain.

Oral glucose tolerance test. An OGTT was performed after a 16-h fast on 7 or 8 female rats in each group (32 animals), aged 11 weeks. Animals were then given $0.7 \mathrm{ml}$ of $50 \%$ glucose solution per $100 \mathrm{~g}$ body weight. Blood samples were collected from the tail vein before gavage and after 15, 30, 60 and $120 \mathrm{~min}$ to measure glucose and insulin concentrations. Plasma samples were kept at $-20^{\circ} \mathrm{C}$ until assayed for insulin. For measurement of glucose concentrations, blood samples were collected on heparinised tubes from which $50 \mu 1$ were transferred to another tube containing $500 \mu \mathrm{l}$ of $\mathrm{HClO}_{4}(0.33 \mathrm{~mol} / \mathrm{l})$ for proteins precipitation. After centrifugation, samples aliquots were kept at $-20^{\circ} \mathrm{C}$ until glucose measurement.

Islet isolation. Pancreatic islets were isolated from the 12week-old female rat offspring by collagenase digestion. In short, the rats were killed and their pancreases extracted, minced and digested in $8 \mathrm{ml}$ HBSS containing $8 \mathrm{mg}$ collagenase type XI (specific activity $1.61 \mathrm{U} / \mathrm{mg}$; Sigma, St. Louis, Mo., USA). The tubes were shaken by hand for $10 \mathrm{~min}$ at $37^{\circ} \mathrm{C}$. The digestion was terminated by adding ice-cold HBSS. Islets were collected and purified twice by centrifugation ( $1 \mathrm{~min}$ at $800 \mathrm{rev} / \mathrm{min}$ ). Then, the tissue was washed 4 times by decantation to remove debris. Finally, islets were isolated by hand picking and cultured in Petri dishes for $24 \mathrm{~h}$ in RPMI 1640 medium (Gibco, Grand Island, N.Y., USA) containing FBS (5\% v/v) and antibiotics (penicillin $200 \mathrm{U} / \mathrm{ml}$, streptomycin $0.2 \mathrm{mg} / \mathrm{ml})$.

Islet treatment. After $24 \mathrm{~h}$ of culture, the islets were rinsed with serum-free DME/F12 medium (1:1 v/v; Gibco) and incubated for the next $48 \mathrm{~h}$ in the same medium with or without $3 \mathrm{mmol} / \mathrm{l}$ taurine (Sigma). During the last $24 \mathrm{~h}$ of taurine treatment, the islets were exposed to a cytokine mixture containing $50 \mathrm{U} / \mathrm{ml} \mathrm{IL} 1-\beta, 100 \mathrm{U} / \mathrm{ml}$ TNF- $\alpha$ and $100 \mathrm{U} / \mathrm{ml} \mathrm{IFN-} \gamma$ (Endogen, Woburn, Mass., USA).

Islet labelling. Apoptosis was detected as DNA strand breakage by the TUNEL method using an In Situ Cell Death Detection Kit (TMR red; Roche Diagnostics, Mannheim, Germany) as described [25]. This kit used tetramethyl-rhodamine-dUTP incubated with the enzyme, deoxynucleotidyl transferase, to label the apoptotic nuclei. DAPI (50 mg/ml; Roche) was used to label the total islet nuclei.

Confocal microscopy. Stained probes were examined through a confocal laser scanning microscopy system (MRC-1024 UV; Bio-Rad, Hemel Hempstead, UK) equipped with argon ion and 
krypton argon ion lasers. Rhodamine was excited at $488 \mathrm{~nm}$ and the emission was measured with a long-pass filter of more than $515 \mathrm{~nm}$; DAPI was excited at $351 \mathrm{~nm}$ and measured at $455 \pm 32 \mathrm{~nm}$. We collected 4 to 5 optical sections at every $10 \mu \mathrm{m}$ through the islets. The number of rhodamine-positive nuclei to the total number of nuclei was reported and expressed as a percentage.

Glucose and insulin measurements. Plasma glucose concentration was determined by the glucose oxidase method using glucose (Trinder's) reagent (Sigma). Plasma insulin concentration was measured by ELISA test using the Mercodia Ultrasensitive Rat Insulin ELISA Kit (Uppsala, Sweden) with variation coefficients of $8.0 \%$ within assays and $4.6 \%$ between assays.

HPLC measurements. Before islet isolation, blood samples were collected. Plasma was diluted 10 times in 35\% 5-sulfosalicylic acid in order to extract the amino acids, and then stored at $-80^{\circ} \mathrm{C}$ until analysis. Analysis and quantification of the amino acids were performed by a standard, reverse-phase HPLC method after derivatisation with o-phtalaldehyde. Identification of separated amino acids was occasionally confirmed by ion exchange chromatography (Model 6300; Beckman, Fullerton, Calif., USA).

Statistical analysis. Experimental results are reported as means \pm SEM. The significance of the difference between groups was analysed by Scheffe's test following one-way or two-way ANOVA. A $p$ value of less than 0.05 was considered statistically significant.

\section{Results}

Effect of an LP diet and taurine supplementation in fetal and early life on body weight and on blood parameters in the adult rat. In 11-week-old female offspring, there was no difference in the body weights between the $\mathrm{C}$ group $(221.2 \pm 3.1 \mathrm{~g})$ and the $\mathrm{R}$ group $(207.8 \pm 4.1 \mathrm{~g})$. Having a normal diet after weaning was sufficient for the rats to catch up a normal body weight in spite of early growth retardation. Taurine supplementation did not modify these body weights in

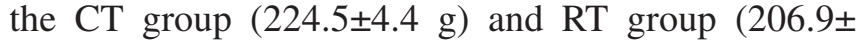
$2.2 \mathrm{~g})$. No difference in taurine level $(\mu \mathrm{mol} / \mathrm{l})$ was observed in the plasma of the adult offspring of the protein-deprived dams $(\mathrm{C}, 453.7 \pm 26.1 ; \mathrm{R}, 417.6 \pm 43.3$; CT, 491.1 \pm 33.1 ; RT, 348.3 \pm 55.9$)$. There were no changes in the other amino acids except the level of cystine ( $\mathrm{R}, 67.2 \pm 4.9$ vs $\mathrm{RT}, 84.3 \pm 1.9 ; p<0.05)$, which was a result of the taurine supplementation.

Fasting plasma insulin and glucose levels are shown in Fig. 1. The insulin level was reduced by $80 \%$ in $\mathrm{R}$ animals compared with in the $\mathrm{C}$ group $(p<0.01)$. The glucose level, however, was marginally but significantly increased in the $\mathrm{R}$ group (12\%; $p<0.05)$. Taurine added to the drinking water tended to restore a normal insulinaemia in the RT group. In contrast, in the CT group, taurine significantly decreased the fasting plasma insulin concentration $(p<0.05)$ but had no effect on the fasting plasma glucose levels.
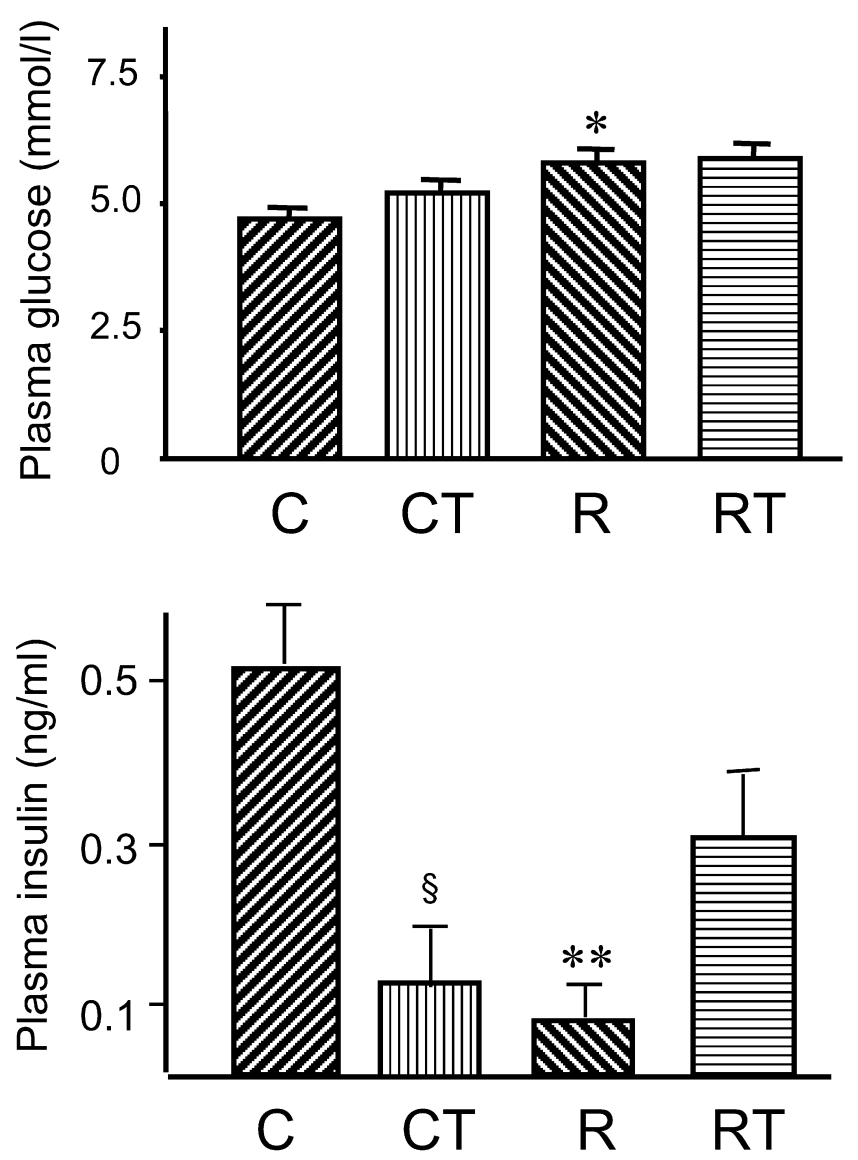

Fig. 1. Effect of an early LP diet, supplemented or not with taurine, on fasting insulin and glucose plasma levels in 11week-old female rats. Animals were born from mothers fed an LP diet (R), a control diet (C), an LP diet with taurine (RT) or a control diet with taurine (CT). Values are means \pm SEM of 7 or 8 animals per group. ${ }^{*} p<0.05$ vs $C$; ${ }^{*} p<0.01$ vs $C$; ${ }^{\S} p<0.05$ vs without taurine in vivo

Effect of an LP diet and taurine supplementation in fetal and early life on glucose tolerance in the adult rat. The plasma insulin and glucose concentrations measured at different times after an oral glucose challenge are shown in Fig. 2. In the $\mathrm{R}$ group, insulin secretion increased only slightly and was significantly lower than that in the $\mathrm{C}$ group $(p<0.05)$. The early response (0-15 min) was particularly blunted. Between 60 and $120 \mathrm{~min}$, the levels of insulin secretion in the two groups ( $\mathrm{C}$ and $\mathrm{R}$ ) were similar. In contrast, during the challenge, glucose concentrations tended to be higher in $\mathrm{R}$ animals than those in $\mathrm{C}$ animals, but this difference was not significant.

Taurine supplementation restored a normal insulin response to the glucose challenge in the RT group $(p<0.05$; Fig. 2) but had no effect on CT animals. It did not affect the plasma glucose levels during the test in the RT group compared with the R group, but it significantly increased that of the CT group $(p<0.05)$. 

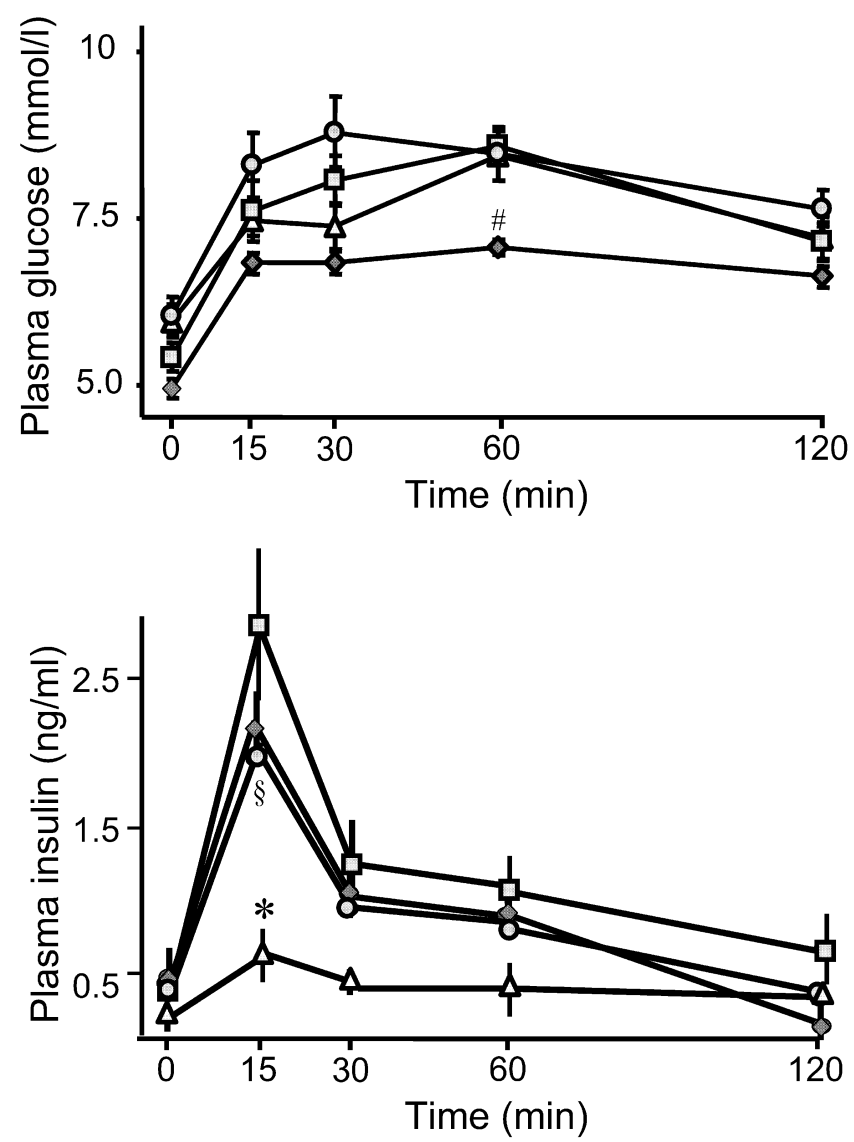

Fig. 2. Glucose tolerance and plasma insulin response of adult (11-week-old) female rats to an oral glucose challenge $(0.7 \mathrm{~g} / \mathrm{kg})$. Animals were born from mothers fed an LP diet $(\mathrm{R}, \triangle)$, a control diet $(\mathrm{C}, \diamond)$, an LP diet with taurine $(\mathrm{RT}, \bigcirc)$ or a control diet with taurine $(\mathrm{CT}, \square)$. Values are means \pm SEM of 7 or 8 animals per group. ${ }^{\#} p<0.05$ vs CT; $* p<0.05$ vs C; ${ }^{\S} p<0.05$ vs R

An LP diet in fetal and early life increased the susceptibility of adult islet cells to cytokines. Adult islets from the C, R, CT and RT groups were cultured and were either treated or not with a cytokine mixture. Apoptosis in the four groups was detected by the TUNEL method. The basal apoptotic rate (without cytokines) in the $\mathrm{R}$ group tended to be higher than that in the $\mathrm{C}$ group, but this difference was not significant (Fig. 3). Cytokine treatment induced a doubling of islet cell apoptosis in the $\mathrm{C}$ group $(p<0.01)$. In the $\mathrm{R}$ group, islet cell apoptosis was increased by $290 \%$ with cytokines treatment $(p<0.01)$, and this increase was significantly higher than in the $\mathrm{C}$ group $(p<0.01)$. Therefore, $\mathrm{R}$ islets were more susceptible to cytokines than $\mathrm{C}$ islets.

Taurine supplementation in vivo and in vitro alters cytokine-induced apoptosis. Supplementation of the maternal diet with taurine had no effect on the basal apoptotic rate in the CT and RT groups. The response to cytokines was greater in CT islets $(p<0.01)$, while taurine lowered the response to cytokines in RT islets $(p<0.01)$.

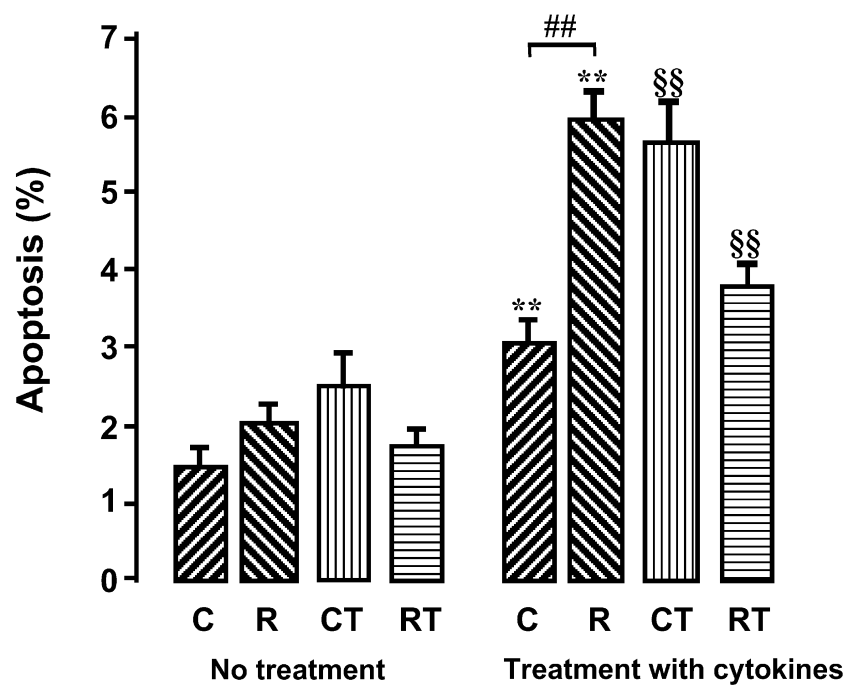

Fig. 3. Effect of an LP diet and taurine supplementation on the sensitivity of adult islets to cytokines (apoptosis). Animals were born from mothers fed an LP diet (R), a control diet (C), an LP diet with taurine (RT) or a control diet with taurine (CT). At 12 weeks of age, islets were isolated and cultivated without or with cytokines (IL-1 $\beta$, TNF- $\alpha$ and IFN- $\gamma$ ) for $24 \mathrm{~h}$. Values are means \pm SEM of three to four separate experiments providing $>4.5 \times 10^{4}$ of islet cells per group. $* * p<0.01$ vs with no treatment; $\$ \S p<0.01$ vs cytokine treatment without taurine supplementation; ${ }^{\# \#} p<0.01 \mathrm{C}$ vs R

Table 1. The effect of cytokine treatment only and of treatment with cytokines and taurine on islet cell apoptosis (\%) in vitro

\begin{tabular}{lll}
\hline Treatment & C group & R group \\
\hline $\begin{array}{lll}\text { No treatment } \\
\text { Cytokines only }\end{array}$ & $1.46 \pm 0.25$ & $2.01 \pm 0.24$ \\
(IL-1 $\beta+T N F \alpha+I F N \gamma)$ & $3.08 \pm 0.27^{\mathrm{a}}$ & $5.93 \pm 0.39^{\mathrm{a}}$ \\
$\begin{array}{l}\text { Cytokines + taurine } \\
\text { in culture medium }(3 \mathrm{mmol} / \mathrm{l})\end{array}$ & $1.68 \pm 0.27^{\mathrm{b}}$ & $3.86 \pm 0.44^{\mathrm{b}}$ \\
\hline
\end{tabular}

Data are means \pm SEM of three to four separate experiments providing $>4.5 \times 10^{4}$ of islet cells per group. ${ }^{\text {a }} p<0.01$ vs without cytokine treatment; ${ }^{\mathrm{b}} p<0.01 \mathrm{vs}$ with cytokine treatment only

The direct in vitro effect of taurine was investigated by incubating $\mathrm{C}$ and $\mathrm{R}$ islets in medium with or without taurine, before cytokine treatment with or without taurine (Table 1). Estimation of apoptosis showed that adding taurine to the culture medium significantly lowered the rate of apoptosis $(p<0.01)$ by $54 \%$ and $65 \%$ in $\mathrm{C}$ and $\mathrm{R}$ islet cells respectively.

\section{Discussion}

Two important findings are reported in this work: (i) that moderate early protein deficiency in a rat diet permanently impairs beta cell physiology, and (ii) that by enhancing the level of taurine to normal after maternal taurine supplementation, such deleterious effects may 
be prevented. We had already observed an increased vulnerability of islets from the offspring of proteinmalnourished dams to cytokines and $\mathrm{NO}$ at fetal age, which was restored by taurine intervention [7]. Normal nutrition after weaning was thus unable to restore normal insulin secretion and normal susceptibility of adult islets to toxic molecules implicated in Type 1 diabetes. Taurine intervention, however, could play a role in the early prevention of Type 1 diabetes.

Although the notion of early programming of Type 1 diabetes, which underlies this work, has not yet been clearly addressed in the literature, early events such as viral infection (in humans [26]), early induction of high levels of glucocorticoids [27] and a higher wave of apoptosis in islets of neonates (in the non-obese diabetic mouse $[28,29])$ have been associated with the later development of Type 1 diabetes.

The possible mechanisms by which early protein restriction induces increased vulnerability of fetal islets to cytokines, and by which taurine prevents this, have already been discussed elsewhere [7]. Maternal malnutrition affects the quality and quantity of the beta cells of the offspring during development, an effect which disappeared in the case of maternal taurine supplementation to the LP diet. The imbalance between lower proliferation and higher apoptotic rate leads to smaller islets and to a reduced beta cell mass lacking the survival factors IGF-1 and IGF-2 at birth and in early life [6]. Lower IGF levels may be involved in the increased vulnerability of fetal islets, since maternal taurine supplementation, which restores beta cell mass and normalises islet vulnerability, rehabilitates IGF levels in the endocrine pancreas [5]. However, other chaperone proteins and proteins involved in the defence mechanism are altered as well and could contribute to the negative picture [30].

The mechanism by which the effect of the nutritional environment persists at age 3 months despite a normal diet after weaning is less clear. Preliminary data on NO production by adult islets in response to cytokines may in part explain the higher apoptotic rate observed in the $\mathrm{R}$ islets after incubation with cytokines. Indeed, NO production was enhanced 5-fold in $\mathrm{R}$ islets compared with $\mathrm{C}$ islets after cytokines stimulation, with no NO being secreted in basal conditions. One may thus suggest that inducible nitric oxide synthase (iNOS) is overexpressed in the R cells when stimulated by cytokines.

Taurine supplementation in vivo protected $\mathrm{R}$ adult islets from cytokine toxicity, but increased islet sensitivity to cytokines in the $\mathrm{C}$ group. A direct positive or negative effect due to differences in plasma taurine levels at the time of analysis cannot be an explanation for these results, since taurine levels were similar in the four groups at 3 months of age. The effect of taurine could result from the fact that taurine administration in fetal and early life led to the development of different beta cell populations in the two groups (CT and RT). We have indeed shown that taurine restored fetal islet vascularisation altered by an LP diet, as well as expression of IGF-2 and vascular endothelial growth factor [5, 24]. Vascularisation and vascular endothelial growth factor are of prime importance for the differentiation of the endocrine pancreas [31], and IGFs, being mitogenic and survival factors, modulate the mass of islet cells $[6,32]$. Different levels of taurine during development may thus provide different populations of islet cells, resulting from an activity of this amino acid on these factors. It is also possible that a precise concentration of the amino acid is required for an appropriate differentiation of the fetal endocrine pancreas, since with respect to beta cell vulnerability, a low supply with the LP diet or an exaggerated supply with taurine administration in controls is deleterious. In addition, our preliminary data on the level of NO produced in the culture medium appear to correspond to the data on vulnerability. RT cells produced 10 times less NO than R cells, while CT cells tended to produce twice as much NO as control cells.

Taurine supplementation during gestation has also been investigated in non-obese diabetic mice, an animal model of Type 1 diabetes, and has been shown to reduce markedly the incidence of insulitis. It also delayed diabetes by 10 weeks, or even prevented it. In this case too, taurine modified the proliferation and apoptotic rate as well as the IGF levels in the islet cells [33].

Taurine added to the culture medium protected $\mathrm{R}$ and $\mathrm{C}$ islets against cytokine cytotoxicity, as already observed in fetal islets [7]. A main explanation for this direct protection might be the stimulation of IGF expression in beta cells, as IGFs can decrease cytokineinduced apoptosis of adult islets by inhibiting iNOS expression [34]. IL-1 $\beta$ stimulates the expression of this enzyme via the transcription factor nuclear factor$\kappa \mathrm{B}(\mathrm{NF \kappa B})$ in beta cells, leading to $\mathrm{NO}$ production and then to beta cell death [35]. In addition, taurine chloramine, the final product of interaction between taurine and $\mathrm{HOCl} / \mathrm{OCl}$, inhibits iNOS in activated macrophages [36]. In fact, taurine chloramine is responsible for the oxidation of $\mathrm{I} \kappa \mathrm{B}$, the inhibitor of $\mathrm{NF \kappa B}$, which leads to NFkB blockage and then to iNOS inhibition [37].

Finally, we observed that protein restriction early in life provoked a lower plasma insulin secretion at adult age in fasting state as well as after an oral glucose challenge, confirming previous results $[3,9]$. In the present work, the deficiency in offspring insulin secretion appears to be worsened by prolonging the protein restriction in the lactating dam. Despite the blunted insulin release, the fasting plasma glucose level was only slightly increased, and plasma glucose remained normal during the OGTT. Normal glucose tolerance with reduced insulin secretion can be explained by an adaptation of peripheral tissues to lower insulin levels, as shown previously $[38,39,40]$. 
In fetal islets, a normal sensitivity to secretagogues was recovered after taurine supplementation to the maternal LP diet [23]. This beneficial effect of taurine persisted at 3 months of age when animals had a normalised serum concentration of taurine. In contrast, we found that taurine given to the control dams during gestation and lactation decreased fasting insulin secretion in adult offspring, while maintaining normal insulin secretion during an oral glucose challenge. The effects of taurine on insulin secretion could be explained by the modification of beta cell population resulting from the changes in development discussed above. However, it is also possible that taurine modified the response of the peripheral tissue to the hormone, an effect which has not yet been documented.

In summary, maternal malnutrition modified the early intrauterine environment as well as the quality of lactation in the rats, thereby influencing beta cell development and creating conditions that could lead to the development of Type 1 diabetes later in life. The use of taurine in Type 1 diabetes prevention, despite the risk of harmful effects if not strictly controlled, is conceivable following further investigation of the mechanisms involved.

Acknowledgements. This work was supported by a grant from the Parthenon Trust (London, UK), by the European Union (contract QLK1-2000-00083) and by a grant from the National Fund of Scientific Research in Belgium.

\section{References}

1. Barker DJ, Hales CN, Fall CH, Osmond C, Phipps K, Clark PM (1993) Type 2 (non-insulin dependent) diabetes mellitus, hypertension and hyperlipidemia (syndrome $\mathrm{X}$ ): relation to reduced fetal growth. Diabetologia 36:62-67

2. Snoeck A, Remacle C, Reusens B, Hoet JJ (1990) Effect of low protein diet during pregnancy on the foetal rat endocrine pancreas. Biol Neonate 57:107-118

3. Dahri S, Snoeck A, Reusens B, Remacle C, Hoet JJ (1991) Islet function in offspring of mothers on low protein diet during gestation. Diabetes 40:115-120

4. Cherif H, Reusens B, Dahri S, Remacle C (2001) A protein-restricted diet during pregnancy alters in vitro insulin secretion from islets of foetal Wistar rats. J Nutr 131: 1555-1559

5. Boujendar S, Reusens B, Merezak S et al. (2002) Taurine supplementation to a low protein diet during foetal and early postnatal life restores a normal proliferation and apoptosis of rat pancreatic islets. Diabetologia 45: 856-866

6. Petrik J, Reusens B, Arany E et al. (1999) A low protein diet alters the balance of islet cell replication and apoptosis in the foetal and neonatal rat and is associated with a reduced pancreatic expression of insulin-like growth factorII. Endocrinol 140:4861-4873

7. Merezak S, Hardikar AA, Yajnik CS, Remacle C, Reusens B (2001) Intrauterine low protein diet increases fetal betacell sensitivity to NO and IL-1 beta: the protective role of taurine. J Endocrinol 171:299-308

8. Dahri S, Reusens B, Remacle C, Hoet JJ (1995) Nutritional influences on pancreatic development and potential links with non-insulin-dependent diabetes. Proc Nutr Soc 54: 345-356

9. Reusens B, Remacle C (2001) Effects of maternal nutrition and metabolism on the developing endocrine pancreas. In: Barker D (ed) Fetal origins of cardiovascular and lung disease. Marcel Dekker, New York, pp 339-358

10. Reusens B, Dahri S, Snoeck A, Bennis-Taleb N, Remacle C, Hoet JJ (1995) Long-term consequences of diabetes and its complications may have a fetal origin: experimental evidence. In: Cowett R (ed.) Diabetes. Nestlé Nutrition Workshop Series 35, Vevey/Raven Press, New York, pp 187-198

11. Jacobsen JG, Smith LH (1968) Biochemistry and physiology of taurine and taurine derivatives. Physiol Rev 48:424-511

12. Sturman JA, Rassin DK, Gaull GE (1993) Taurine in development. Physiol Rev 73:119-147

13. Lourenco R, Camilo ME (2002) Taurine: a conditionally essential amino acid in humans? An overview in health and disease. Nutr Hosp 17:262-270

14. Huxtable RJ (1992) Physiological actions of taurine. Physiol Rev 72:101-163

15. Hansen SH (2001) The role of taurine in diabetes and the development of diabetic complications. Diabetes Metabol Res Rev 17:330-346

16. Tokumaga H, Yoneda Y, Kuriyama K (1979) Protective effects of taurine against streptozotocin-induced hyperglycaemia. Biochem Pharmacol 28:2807-2811

17. Maturo J, Kulakowski EC (1988) Taurine binding to the purified insulin receptor. Biochem Pharmacol 37:3755-3760

18. Cherif H, Reusens B, Dahri S, Remacle C, Hoet JJ (1996) Stimulatory effects of taurine on insulin secretion by foetal rat islets cultured in vitro. J Endocrinol 151:501-506

19. Shaffer WS, Nguyen K, Ballard S, Gardner N, Azuma J (1996) Regulation of $\mathrm{Ca}^{2+}$ transport by insulin and taurine. Interaction at the level of the $\mathrm{Na}^{+}-\mathrm{Ca}^{2+}$ exchange. In: Huxtable RJ, Azuma J, Kuriyama K, Nakagawa M, Baba A (eds) Taurine 2: basic and clinical aspects. Plenum Press, New York, pp 551-560

20. Bustamante J, Lobo MV, Alonso FJ et al. (2001) An osmotic-sensitive taurine pool is localized in rat pancreatic islet cells containing glucagon and somatostatin. Am J Physiol 281:E1275-1285

21. Wang JH, Redmond HP, Watson WG, Condrom C, BouchierHeyes D (1996) The beneficial effect of taurine on the prevention of human endothelial cell death. Shock 6: 331-338

22. Neary P, Cordron C, Kilbaugh T, Redmond PH, BouchierHayes D (1997) Taurine inhibits Fas mediated neutrophil apoptosis. Shock 7:120

23. Cherif H, Reusens B, Ahn MT, Hoet JJ, Remacle C (1998) Effects of taurine on the insulin secretion of rat foetal islets from dams fed a low protein diet. J Endocrinol 159:341-348

24. Boujendar S, Arany E, Hill D, Remacle C, Reusens B (2003) Taurine supplementation to a low protein diet during foetal life restores a normal vascularization of the rat endocrine pancreas. J Nutrition 133:2820-2825

25. Sgonc R, Boeck G, Dietrich H, Gruber J, Reicheis H, Wick G (1994) Simultaneous determination of all cell surface antigens and apoptosis. Trends Gene 10:41-42

26. Hyöty H, Taylor KW (2002) The role of viruses in human diabetes. Diabetologia 45:1353-1361

27. Kim KS, Kang Y, Choi SE et al. (2002) Modulation of glucocorticoid-induced GAD expression in pancreatic beta cells by transcriptional activation of the GAD67 promoter and its possible effect on the development of diabetes. Diabetes 51:2764-2772

28. O'Brien BA, Fieldus WE, Field CJ, Finegood DT (2002) Clearance of apoptotic beta-cells is reduced in neonatal au- 
toimmune diabetes-prone rats. Cell Death Differ 9:457464

29. Trudeau JD, Dutz JP, Arany E, Hill DJ, Fieldus WE, Finegood WE (2000) Neonatal beta-cell apoptosis: a trigger for autoimmune diabetes? Diabetes 49:1-7

30. Sparre T, Reusens B, Cherif H et al. (2003) Intrauterine programming of fetal islet gene expression-effects of maternal protein restriction during gestation revealed by proteome analysis. Diabetologia 46:1497-1511

31. Lammert E, Cleaver O, Melton D (2001) Induction of pancreatic differentiation by signals from blood vessels. Science 294:564-567

32. Petrik J, Arany E, McDonald TJ, Hill DJ (1998) Apoptosis in the pancreatic islet cells of the neonatal rat is associated with a reduced expression of Insulin-Like Growth Factor II that may act as a survival factor. Endocrinol 139:2994-3004

33. Arany E, Brenda S, Reusens B, Remacle C, Hill D (2002) Delayed onset of diabetes in NOD mice caused by early dietary supplementation with taurine involves a changed development of the endocrine pancreas. Diabetes 51 [Suppl 2]:1536

34. Mabley JG, Belin V, John N, Green IC (1997) Insulin-like growth factor I reverses interleukin-1beta inhibition of insulin secretion, induction of nitric oxide synthase and cytokine-mediated apoptosis in rat islets of Langerhans. FEBS Lett 417:235-238
35. Kwon G, Corbett JA, Rodi CP, Sullivan P, McDaniel ML (1995) Interleukin-1 beta-induced nitric oxide synthase expression by rat pancreatic beta-cells: evidence for the involvement of nuclear factor kappa $\mathrm{B}$ in the signalling mechanism. Endocrinology 136:4790-4795

36. Barua M, Liu Y, Quinn MR (2001) Taurine chloramine inhibits inducible nitric oxide synthase and TNF $\alpha$ gene expression in activated anlveolar macrophages: decreased NFkB activation and IkB kinase activity. J Immunol 167: 2275-2281

37. Kanayama A, Inoue JI, Konishi YS, Shimizu M, Miyamoto $\mathrm{Y}$ (2002) Oxidation of IkB-alpha at Methionine 45 is one cause of taurine chloramine-induced inhibition of NF kappa B activation. J Biol Chem 277:24049-24056

38. Ozanne SE, Wang CL, Coleman N, Smith GD (1996) Altered muscle insulin sensitivity in the male offspring of protein-malnourished rats. Am J Physiol 271:E1128-1134

39. Shepherd PR, Crowther NJ, Desai M, Hales CN, Ozanne SE (1997) Altered adipocyte properties in the offspring of protein malnourished rats. British J Nutr 78:121-129

40. Holness MJ, Fryer LG, Sugden MC (1999) Protein restriction during early development enhances insulin responsiveness but selectively impairs sensitivity to insulin at low concentrations in white adipose tissue during a later pregnancy. British J Nutr 81:481-489 